\title{
En previsión de la próxima pandemia*
}

\author{
Michael T. Osterholm
}

\section{El miedo mismo}

Desde la antigüedad, las pandemias de influenza han representado las mayores amenazas de calamidad universal causada por una enfermedad infecciosa. En los 300 años pasados han ocurrido 10 pandemias de influenza entre humanos. Las más recientes se produjeron en 1957-1958 y 1968-1969; aunque decenas de miles de estadounidenses perecieron en cada una, se les consideró leves en comparación con otras como la pandemia de 1918-1919, que, según análisis recientes, causó la muerte de entre 50 y 100 millones de personas en el mundo. Hoy, con una población mundial de 6500 millones, tres veces mayor a la de 1918, hasta una pandemia "leve" podría acabar con muchos millones de personas.

Varios acontecimientos y factores recientes han elevado en forma significativa la preocupación de que sea inminente una pandemia específica a corto plazo. Podría ser causada por la H5N1, la cepa de influenza aviar que circula actualmente en Asia. En esta encrucijada los científicos no pueden estar seguros, ni saber con exactitud en qué momento atacará una pandemia, ni si rivalizará con la experiencia de 1918-1919 o será más benigna, como las de 1957-1958 y 1968-1969. Sin embargo, la realidad de una próxima pandemia no puede evitarse; sólo se puede amenguar su impacto. Ya se llevan a cabo algunos esfuerzos preparatorios, pero en muchos niveles de la sociedad es necesario que las instituciones hagan mucho más.

\section{EI contexto}

De los tres tipos de virus de la influenza, el tipo A infecta y mata al mayor número de personas cada año y es el único que causa pandemias. Se origina en aves acuáticas silvestres. El virus no causa enfermedades en las aves $y$, si bien se transmite considerablemente entre ellas, no experimenta cambios genéticos significativos.

No se ha comprobado la transmisión directa de aves a humanos, pero cuando un virus se transmite de aves silvestres a domésticas, como las aves de corral, experimenta cambios que le permiten infectar a humanos, cerdos y, potencialmente, otros mamíferos. Una vez en las células pulmonares de un huésped mamífero, el virus puede cambiar de composición o mezclar genes con virus de la influenza humana que estén presentes. Este proceso puede conducir a una cepa viral completamente nueva, capaz de una transmisión sostenida de humano a humano. Si tal virus no ha circulado antes en humanos, la población entera será susceptible. Y si no ha circulado en la población humana durante cierto número de años, la mayoría de las personas carecerán de inmunidad residual de la infección anterior.

Una vez que la nueva cepa se adapta mejor a los humanos y se transmite con facilidad de persona a persona, es capaz de causar una nueva pandemia. Como pasa en repetidas ocasiones de un humano a otro, a la larga se vuelve menos virulenta y se une a los otros virus de influenza que circulan por el globo cada año. Este ciclo continúa hasta que otro virus nuevo surge de las aves silvestres y el proceso comienza otra vez.

Algunas pandemias ocasionan tasas mucho más altas de infección y fallecimientos que otras. Los científicos entienden hoy día que esta variación es resultado de la construcción genética de cada virus específico y de la presencia de ciertos factores de virulencia. Por eso la pandemia de 1918-1919 mató mucho más personas que las de 1957-1958 y 1968-1969.

\footnotetext{
* Este trabajo fue publicado originalmente en Foreign Affairs en Español, octubre-diciembre 2005 y se reproduce con autorización del editor.
} 


\section{Una diferencia esencial}

Las enfermedades infecciosas siguen siendo la principal causa de mortalidad humana en el mundo. Hoy día más de 39 millones de personas viven con el VIH, y el año pasado unos 2.9 millones murieron de sida, lo cual llevó el total acumulado de fallecimientos por esa enfermedad a unos 25 millones. También la tuberculosis (TB) y la malaria continúan siendo causas importantes de muerte. En 2003, unos 8.8 millones de personas se infectaron de TB, enfermedad que causó más de 2 millones de fallecimientos. Cada año la malaria ocasiona más de un millón de muertes y cerca de 5000 millones de episodios de enfermedad crítica. Además, infecciones de reciente surgimiento, enfermedades diarreicas y otras transmitidas por vectores, así como agentes resistentes a antibióticos, plantean una seria y creciente preocupación en materia de salud.

Dado que hay tantas otras enfermedades infecciosas significativas, ¿por qué otra pandemia de influenza merece atención singular y urgente? En primer lugar, de los más de 1500 microbios de los que se sabe que causan enfermedades en humanos, la influenza sigue siendo el rey en términos de mortalidad global. Incluso en un año en el que sólo circulan las variedades de jardín, se estima que 1-1.5 millones de personas perecen de infecciones de influenza o complicaciones relacionadas. En una pandemia que dure de 12 a 36 meses, el número de casos y de muertes se eleva en forma dramática.

Pruebas clínicas, epidemiológicas y de laboratorio obtenidas en fechas recientes indican que el impacto de una pandemia causada por la actual cepa H5N1 sería similar al de la pandemia de 1918-1919. Más de la mitad de las personas fallecidas en esa pandemia tenían entre 18 y 40 años de edad y habían gozado de buena salud. Si los datos de mortalidad de esos años se extrapolan a la población actual de Estados Unidos, 1.7 millones de personas podrían morir, la mitad entre las edades de 18 y 40 años. A escala global, esos mismos cálculos arrojan 180-360 millones de muertes, más de cinco veces el número acumulado de muertes documentadas por sida. En 1918-1919 la mayoría de las muertes fue causada por la respuesta, inducida por el virus, del sistema inmune de la víctima -una invasión de citocinas-, que condujo al síndrome de perturbación respiratoria aguda (ARDS, por sus siglas en inglés). En otras palabras, en el proceso de combatir la enfermedad el sistema inmune de una persona causó grave daño a los pulmones, lo cual condujo a la muerte. Víctimas del H5N1 también han padecido tormentas de citocinas, y el mundo no está mucho mejor preparado hoy para atender millones de casos de ARDS que hace
85 años. En las pandemias de 1957-1958 y 1968-1969, la causa primaria de muerte fueron las neumonías bacteriales secundarias que infectaron los pulmones debilitados por la influenza. Si bien a menudo es posible tratar esas infecciones bacteriales con antibióticos, estos medicamentos no estarán disponibles o serán escasos para gran parte de la población mundial durante una pandemia.

La llegada de una pandemia de influenza desencadenará una reacción que podría cambiar el mundo de la noche a la mañana. Durante cierto número de meses posteriores al brote no habrá vacuna disponible, y las existencias de fármacos antivirales son muy limitadas. Además, sólo unas cuantas zonas privilegiadas del planeta tienen acceso a instalaciones de producción de vacunas. El comercio y los viajes internacionales se restringirán e, incluso, se suspenderán en un intento por evitar que el virus entre a más países; tales esfuerzos probablemente fracasarán dada la infecciosidad de la influenza y el volumen de cruces indocumentados que ocurren en la mayoría de las fronteras. Es probable que también en lo interno se limite el transporte de manera significativa, pues se buscará confinar la enfermedad en comunidades pequeñas. El mundo depende de la rápida distribución de productos como alimentos y partes de repuesto para equipos. Las economías globales, regionales y nacionales tendrán que hacer una parada brusca, cosa que jamás ha ocurrido a causa del VIH, la malaria o la tuberculosis, pese a su dramático impacto en el mundo en desarrollo.

El máximo acercamiento que el mundo ha tenido a este escenario en tiempos modernos fue la crisis del SARS (siglas en inglés de síndrome respiratorio agudo severo) en 2003. En un periodo de cinco meses, unas 8000 personas fueron infectadas por un nuevo coronavirus humano. De ellas, 10\% murieron. Al parecer, el virus se propagó a humanos cuando se vendieron animales infectados y se sacrificaron en atiborrados mercados de la provincia de Guangdong, China, que no reunían condiciones sanitarias adecuadas. Si bien la tasa de transmisión del SARS palidece en comparación con la de la influenza, demostró con qué rapidez puede circular por el globo un agente infeccioso semejante, dada la facilidad y frecuencia de los viajes internacionales. Una vez que el SARS brotó en la China rural, se extendió a cinco países en 24 horas y a tres de seis continentes en cuestión de meses.

La experiencia del SARS constituye una lección crítica respecto de la potencial respuesta global a una influenza pandémica. Incluso con el número relativamente bajo de muertes que causó en comparación con otras enfermedades infecciosas, el SARS tuvo un poderoso impacto psicológico negativo en la población 
de muchos países. En un reciente análisis de la epidemia, el Instituto de Medicina de la Academia Nacional de Ciencia concluyó: "La razón relativamente alta de casos de fallecimientos, la identificación de superpropagadores, la novedad de la enfermedad, la velocidad de su expansión global y la incertidumbre del público respecto de la capacidad de controlar su diseminación pudieron contribuir a la alarma pública. Esta alarma, a su vez, pudo conducir al comportamiento que agudizó los golpes económicos a las industrias de viajes y turismo de las naciones donde ocurrió el mayor número de casos".

El SARS dio una probada del impacto que una pandemia asesina de influenza tendría sobre la economía global. Jong-Wha Lee, de la Universidad de Corea, y Warwick McKibbin, de la Universidad Nacional de Australia, estimaron en 40000 millones de dólares el impacto económico de los seis meses que duró la epidemia del SARS en la región Asia-Pacífico. En Canadá, 438 personas sufrieron el contagio y 43 murieron después que una persona infectada viajó de Hong Kong a Toronto, y la Comisión de Turismo de Canadá calculó que la epidemia costó 419 millones a la economía del país. El ministro de Salud de Ontario estimó que el SARS costaría unos 763 millones al sistema de salud de la provincia, dinero que se gastó, en parte, en clínicas especializadas en ese mal y en suministros para proteger a los trabajadores de la salud. El brote de SARS también tuvo impacto sustancial en la industria global de aviación. Después que la enfermedad surgió en 2003, los vuelos en la región Asia-Pacífico se redujeron en $45 \%$ respecto del año anterior. Durante el brote, el número de vuelos entre Hong Kong y Estados Unidos cayó $69 \%$. Y este impacto palidecería en comparación con el de una pandemia de influenza que se extendiera entre 12 y 36 meses.

La epidemia del SARS también plantea preguntas respecto de lo bien preparados que están los gobiernos para hacer frente a una crisis prolongada por causa de una enfermedad infecciosa, en particular, los que ya son inestables. Yanzhong Huang, de la Universidad Seton Hall, en Estados Unidos de América (EUA), concluyó que la epidemia de SARS creó la más tensa crisis social y política enfrentada por los gobernantes chinos desde la represión de Tiananmen. Es probable que los problemas de China fueran resultado menos del impacto en la salud pública que del esfuerzo fallido por contener el pánico, ocultando al pueblo información sobre la enfermedad. El esfuerzo fue contraproducente. Durante la crisis, el primer ministro Wen Jiabao indicó, en una reunión de gabinete referente a la epidemia, que "la salud y seguridad del pueblo, el estado general de la reforma, el desarrollo y la estabilidad, y el interés nacional y la imagen de China están en juego". Sin embargo, Huang cree que "un periodo fatal de vacilación en compartir información y entrar en acción propició que se esparcieran ansiedad, pánico y rumores por todo el país, y minó los esfuerzos del gobierno por crear una imagen más benigna de sí mismo en la arena internacional".

Una infección extendida y el colapso económico pueden desestabilizar a un gobierno; la culpa de no atender con eficacia una pandemia puede baldarlo. Esto es aún más aplicable a una pandemia de influenza. En caso de que surja, el nivel de pánico presenciado durante la crisis del SARS podría crecer a proporciones fuera de control conforme los contagios y decesos sigan acumulándose con el paso de los meses. Por desgracia, el público es a menudo indiferente a las advertencias iniciales sobre crisis inminentes causadas por enfermedades infecciosas, como ocurrió con el VIH, por ejemplo. La indiferencia se transforma en miedo sólo después de que la catástrofe se presenta, cuando ya es demasiado tarde para aplicar medidas preventivas o de control.

\section{Preparados para lo peor}

¿Qué debe hacer el mundo industrializado en preparación a la próxima pandemia? La respuesta es sencilla: mucho más. Hasta ahora, la Organización Mundial de la Salud y varios países han completado o esbozado planes útiles, pero demasiado generales. La Secretaría de Salud y Servicios Humanos del gobierno estadounidense ha incrementado investigaciones sobre producción y disponibilidad de vacunas. Estos esfuerzos son loables, pero lo que se requiere es un detallado programa operativo referente a la forma de guiar a la población para sortear una pandemia de entre uno y tres años de duración. Dicho proyecto debe involucrar a todos los componentes clave de la sociedad. En el sector privado, debe coordinar las respuestas de la comunidad médica, proveedores médicos, proveedores de alimentos y el sistema de transporte. En el sector gubernamental, debe tomar en cuenta a funcionarios de salud pública, aplicación de la ley y manejo de emergencias en los niveles internacional, federal, estatal y local.

Al mismo tiempo se debe reconocer que tales programas maestros pueden tener sus desventajas. Aaron Wildavsky, de la Universidad de California en Berkeley, ha argüido en forma convincente que la capacidad de recuperación es la verdadera clave para el manejo de crisis: los planes demasiado rígidos pueden causar más daño que provecho. Aun así, la planeación es de enorme utilidad. Da a funcionarios del gobierno, socios 
del sector privado y a la comunidad la oportunidad de reunirse, de reflexionar sobre dilemas potenciales, adquirir equipo necesario y preparar estructuras organizativas para una respuesta de 12 a 36 meses. Un programa obliga a los dirigentes a ensayar sus respuestas a la crisis, prepararse en lo emocional y lo intelectual para que cuando llegue el desastre la comunidad pueda enfrentarlo.

La producción de vacunas contra la influenza merece especial atención. Debe desarrollarse una iniciativa para ofrecer una vacuna al mundo entero, con un calendario bien definido que garantice el avance. Es loable que países como EUA y Vietnam lleven a cabo programas con objetivos de largo plazo para desarrollar y producir vacunas contra el $\mathrm{H} 5 \mathrm{~N} 1$ para sus respectivas poblaciones; pero si el resto del mundo carece de suministros, hasta los vacunados serán devastados cuando la economía mundial se detenga en seco. La preparación para la influenza pandémica es, por naturaleza, un asunto internacional: nadie puede aislarse de una pandemia.

El colapso del comercio mundial originado por la pandemia, y su propagación a las naciones tanto industrializadas como en desarrollo, representarían la primera prueba real de la capacidad de recuperación del sistema global de entregas. Dada la extensión en la que el comercio moderno se apoya en el intercambio preciso y ágil de bienes y servicios, una paralización del sistema económico global causaría un daño dramático a la capacidad mundial de atender la creciente demanda de bienes esenciales como alimentos y medicinas durante una crisis. La comunidad empresarial ya no puede darse el lujo de contentarse con un papel marginal en la planeación de la respuesta a una pandemia. Para que el mundo disponga de bienes y servicios críticos durante esa emergencia, los dirigentes industriales deben acumular materias primas para la producción y planear la distribución y el apoyo de transporte. Los directivos de cada compañía deben estar listos a responder con rapidez a los cambios en la disponibilidad, producción, distribución y manejo de inventarios de sus productos. No existe un modelo para revivir la actual economía global en caso de que fuera devastada.

Para ser de verdad completa, toda planeación en los niveles internacional, regional, nacional y local debe considerar tres escenarios diferentes: $i y$ si la pandemia empieza esta noche? ¿Y si empieza de aquí a un año? ¿Y si el mundo tiene la fortuna de contar con toda una década para prepararse? Todas son posibles, ninguna es segura.

\section{Comenzar esta noche}

¿Qué ocurriría hoy en la oficina del gobernante de cada nación si varias ciudades de Vietnam sufrieran de brotes importantes de una infección por H5N1, con una tasa de mortalidad de $5 \%$ ? Primero, habría un esfuerzo inmediato por tratar de ordenar datos dispersos de vigilancia sanitaria de una variedad de fuentes gubernamentales y de salud pública para determinar qué países podrían tener casos relacionados con la pandemia. Luego, es probable que tuviera que tomarse la decisión de cerrar la mayoría de las fronteras internacionales e, incluso, algunas estatales o provinciales, sin ningún criterio predeterminado sobre la forma o el momento en que volverían a abrirse. La seguridad fronteriza se volvería prioritaria, en especial, para proteger reservas potenciales de vacunas específicas para la pandemia frente a países cercanos desesperados. Los jefes militares tendrían que desarrollar estrategias para defender el país y también protegerlo contra la insurgencia interna, con fuerzas armadas que probablemente estarían comprometidas por la enfermedad. Incluso en naciones no afectadas, el pánico y el caos se esparcirían conforme los medios internacionales informaran del avance cotidiano del mal en el mundo.

En breve plazo, la economía global quedaría paralizada. Se tendrían que identificar los bienes y servicios que los países necesitarían para "sobrevivir" en los siguientes 12 a 36 meses. En la actualidad, la mayoría de los planes de continuidad de las empresas toman en cuenta sólo una interrupción localizada, por ejemplo, el cierre de una planta, y no han planeado para casos de desabastos extensos de largo plazo. Los sectores privado y público tendrían que desarrollar planes de emergencia para sostener cadenas domésticas de suministro esencial y la producción y distribución de manufacturas y productos agrícolas. La fuerza de trabajo estaría gravemente afectada cuando más se le necesite. En el curso de un año, hasta $50 \%$ de las poblaciones afectadas podrían enfermar y hasta $5 \%$ de ellas podrían morir. El padecimiento golpearía a la alta gerencia con la misma dureza que al resto de la fuerza laboral. En todos los países habría gran escasez de una amplia gama de artículos como alimentos, jabón, papel, focos eléctricos, gasolina, repuestos para equipo militar y bombas de suministro municipal de agua, así como medicinas e, incluso vacunas no relacionadas con la pandemia. Muchas industrias no esenciales para la supervivencia -electrónica, automotriz y del vestido, por ejemplo- sufrirían pérdidas o incluso cerrarían. Actividades que requieren contacto 
humano estrecho -la escuela, ir al cine o comer en restaurantes- se evitarían y tal vez se prohibirían.

La vacuna no tendría impacto en el curso del virus en los primeros meses, y probablemente desempeñaría un papel extremadamente limitado en el mundo durante los 12 a 18 meses siguientes. Pese a importantes innovaciones en la elaboración de la mayoría de las otras vacunas, la producción internacional de la vacuna de la influenza se basa en un sistema frágil y limitado que utiliza tecnología de la década de 1950. La producción anual de vacuna de la influenza en estos días se limita a 300 millones de dosis trivalentes -protegen contra tres diferentes cepas del virus en una dosis-, o menos de 1000 millones de dosis monovalentes. Para contrarrestar una nueva cepa de influenza pandémica que jamás haya circulado entre la población, cada persona requeriría probablemente dos dosis para una protección adecuada. Con la limitada capacidad de producción actual, eso significaría que menos de 500 millones de personas -alrededor de $14 \%$ de la población mundial- estarían vacunadas en el primer año de la pandemia. Además, como la estructura del virus cambia con tanta rapidez, el desarrollo de vacunas sólo podría comenzar una vez que se declarara la pandemia, pues los fabricantes tendrían que obtener la nueva cepa. Pasarían al menos seis meses más para que la vacuna se produjera en masa.

Aun si el sistema funcionara al máximo de su capacidad, la vacuna contra la influenza se produce comercialmente sólo en nueve países: Alemania, Australia, Canadá, Estados Unidos, Francia, Holanda, Italia, Japón y el Reino Unido. Estos países contienen sólo 12\% de la población del planeta. En caso de una pandemia de influenza, es probable que nacionalizaran sus instalaciones de producción doméstica, como ocurrió en 1976, cuando Estados Unidos, previendo una pandemia de influenza del cerdo (H1N1), rehusó compartir su vacuna.

Si una pandemia azotara al mundo hoy, habría otra posible arma contra la influenza: la medicina antiviral. Si se toman a diario durante el tiempo de exposición a la enfermedad, los antivirales han prevenido contagios individuales. También han reducido la gravedad del mal y las complicaciones subsecuentes cuando se toman dentro de las 48 horas siguientes al brote. Si bien no existen datos respecto del H5N1, se da por sentado que los antivirales también evitarían la infección con este virus si se toman antes de la exposición. Sin embargo, no hay pruebas de que los actuales medicamentos contra el virus de la influenza ayuden si el paciente desarrolló la invasión de citocinas que ha caracterizado las recientes infecciones de H5N1. Pero de no mediar tal complicación, el H5N1 debe ser tratable con Tamiflu (fosfato de oseltamivir), fabricado por los laboratorios Roche en una sola planta ubicada en Suiza.

En respuesta a una pandemia, el Tamiflu podría tener impacto mensurable en el limitado número de países que cuentan con reservas significativas, pero no estará disponible en la mayor parte del globo. Si bien la compañía planea abrir otra instalación en EUA este año, la producción anual cubriría sólo un pequeño porcentaje de la población mundial. A la fecha, al menos 14 países han ordenado Tamiflu, pero el monto de estos pedidos apenas es suficiente para atender a $40 \mathrm{mi}-$ llones de personas. Los pedidos requieren de un tiempo considerable de proceso y entrega -la fabricación tarda hasta un año-, y en una emergencia la capacidad de la empresa de producir más sería limitada. Al igual que con las vacunas, es probable que los gobiernos nacionalicen sus existencias de antivirales durante una pandemia. Y aun si el medicamento estuviera disponible, la mayoría de los países no podrían costearlo. También habría escasez de antibióticos críticos para el tratamiento de infecciones bacteriales secundarias. Aun ahora existen reservas limitadas de ocho diferentes agentes antiinfecciosos en EUA, debido a problemas de fabricación.

Además de la medicación, muchos países carecerían de capacidad para hacer frente al aumento en la demanda de suministros y servicios de atención a la salud que normalmente se dan por sentados. En EUA, por ejemplo, existen 105000 ventiladores mecánicos para asistir la respiración mermada, de los cuales entre 75000 y 80000 son usados para cuidado cotidiano de la salud. Durante una temporada rutinaria de influenza, el número de ventiladores en uso se dispara a 100 000. En una pandemia de influenza, Estados Unidos podría necesitar varios cientos de miles de ventiladores adicionales.

Una situación similar existe en todos los países desarrollados. Prácticamente habría escasez de todas las piezas de equipo médico o de protección a los pocos días de reconocerse la pandemia. Durante la crisis, muchos de estos artículos necesarios estarían fuera del alcance de la mayoría de las instituciones de atención a la salud. En la actualidad, dos empresas estadounidenses proporcionan casi todas las máscaras de protección respiratoria para la mayoría de trabajadores de atención a la salud en el mundo. Ninguna de las dos estaría en condiciones de atender el aumento de la demanda, en parte porque los componentes para las máscaras proceden de múltiples proveedores en muchos países. Al restringirse el viaje y el transporte, las máscaras ni siquiera se fabricarían.

Los proveedores de servicios de salud y las organizaciones de atención tampoco están preparados para 
un brote de influenza pandémica que surgiera hoy. Habría una tremenda demanda de profesionales capacitados en atención de la salud. Habría que dotar de personal a "hospitales" ubicados en gimnasios escolares y centros comunitarios para entre uno y tres años. Es probable que esos trabajadores enfermaran y perecieran a la misma tasa que el público y quizá con más frecuencia, sobre todo si carecen de acceso a equipo protector. Sin esos suministros esenciales no está claro cuántos profesionales continuarían expuestos a situaciones de alto riesgo para cuidar a los infectados. Sería necesario entonces encontrar y reclutar voluntarios que fueran naturalmente inmunes por haber sobrevivido a una infección de influenza, lo cual implicaría hacer frente a la fuerte resistencia de la comunidad médica a utilizar voluntarios legos, basada tanto en preocupaciones de responsabilidad civil como en arrogancia profesional.

Habrá que atender otros asuntos desagradables. ¿Quién tendrá acceso prioritario a las reservas extremadamente limitadas de antivirales? El público consideraría injusta cualquier fijación ad hoc de prioridades, lo cual crearía mayor disidencia y perturbación durante una pandemia. Además, no habría siquiera planes detallados para manejar el número masivo de cadáveres que pronto rebasarían la capacidad de procesarlos. Resulta claro que una pandemia de influenza que atacara hoy requeriría de una respuesta médica y no médica sin precedentes. Requiere una planeación que vaya mucho más allá de cualquiera llevada a cabo hasta la fecha por cualquiera de los países y organizaciones del mundo.

\section{De aquí a un año}

Aun si una pandemia de H5N1 estuviera a un año de distancia, el mundo debe prepararse para los mismos problemas con idéntico fervor. Deben emprenderse grandes campañas para preparar a los sectores médicos y no médicos. La planeación para la pandemia debe estar en el programa de cada consejo escolar, planta industrial, firma de inversión, depósito de cadáveres, legislatura estatal y distribuidor de alimentos en EUA y demás países. Existe una necesidad urgente de revaluar la vulnerabilidad de la economía global para garantizar la atención de los aumentos de la demanda. Deben almacenarse productos críticos de consumo y de atención a la salud. Los profesionales de la salud deben aprender a comunicar mejor el riesgo y deben ser capaces tanto de informar los hechos como de reconocer lo que ignoran ante un público atemorizado o en pánico.

Si existe un año de distancia antes de la pandemia, la vacuna podría tener un papel más importante en la respuesta global. Si bien el mundo tendría aún capacidad limitada para fabricar la vacuna contra la influenza, las técnicas que pudieran permitir a los científicos obtener múltiples dosis a partir de una dosis única actual podrían incrementar la oferta. Además de mayor investigación sobre el tema, es preciso asegurar la disponibilidad de jeringas y equipo para administrar la vacuna. Debe haber también un plan internacional sobre la forma en que se distribuirá la vacuna. Es mucho mejor lidiar ahora, en un foro público, con los aspectos éticos relativos a la definición de prioridades, que esperar hasta que la crisis ocurra.

Asimismo, se debe mejorar la prevención y dar prioridad a la intervención temprana y a la evaluación de riesgos. Se debe lanzar de inmediato una agenda de investigación intensiva y amplia para estudiar la ecología y biología del virus de la influenza y el papel epidemiológico de varias especies de animales, sobre todo aves.

\section{Diez años después}

Si las naciones desarrolladas comienzan a transformar de manera radical el actual sistema de producción de la vacuna de la influenza, una pandemia que surgiera de aquí a diez años podría tener un resultado mucho menos devastador. El mundo industrializado debe emprender un proyecto internacional para desarrollar la capacidad de producir una vacuna para toda la población del planeta en los primeros meses de la pandemia. Tal iniciativa debe tener alta prioridad en el Grupo de los Siete países industrializados más Rusia (G-8), porque casi nada puede infligir más muerte y perturbación que una pandemia de influenza.

La actual ley BioShield (BioEscudo) y la legislación adicional presentada a consideración del Congreso estadounidense permitirá elevar la disponibilidad de vacunas en EUA. Este objetivo es loable, pero poco hace para atender necesidades internacionales. La meta final debe ser desarrollar una nueva vacuna de cultivo de células o con otra tecnología comparable que trabaje sobre los subtipos de la influenza y pueda ponerse en poco tiempo al alcance de toda la población mundial.

\section{¿Qué camino tomar?}

El mundo debe formar un mejor entendimiento del potencial de que surja una cepa de una pandemia de influenza. Viene una pandemia: puede ser causada por el H5N1 o por otra cepa nueva. Puede ocurrir hoy, el año próximo, o de aquí a diez años.

Los signos son alarmantes: el número de infecciones por $\mathrm{H} 5 \mathrm{~N} 1$ en animales y humanos se ha venido incrementando; se han documentado pequeños gru- 
pos de casos, lo cual sugiere que el virus podría acercarse a una transmisión sostenida de humano a humano, y el H5N1 continúa evolucionando en el laboratorio virtual de reordenamiento genético que suministra el número sin precedentes de personas, cerdos y aves de corral en Asia. La explosión demográfica en China y otros países asiáticos ha creado un increíble tazón de mezcla para el virus. Considérese esta tranquilizadora información: la más reciente pandemia de influenza, la de 1968-1969, surgió en China cuando su población era de 790 millones; hoy es de 1300 millones. En 1968 el número de cerdos en China era 5.2 millones; hoy son 508 millones. La cifra de aves de corral en China en 1968 era de 12.3 millones; hoy son 13000 millones. Los cambios en otros países asiáticos son similares. Ante estos sucesos, así como el crecimiento exponencial del viaje al extranjero en los 50 últimos años, una pandemia de influenza podría ser más devastadora que nunca.

¿Puede evitarse un desastre? La respuesta es un sí calificado. Si bien no puede evitarse que llegue una pandemia, su impacto puede amenguarse en forma considerable. Depende de la forma en que los dirigentes del mundo -desde los mandatarios del G-8 hasta las autoridades locales- decidan responder. Deben reconocer la amenaza económica, de seguridad y sanitaria que plantea la próxima pandemia de influenza y realizar inversiones en la proporción correspondiente. Cada dirigente debe darse cuenta de que aun si un país cuenta con vacunas suficientes para proteger a sus ciudadanos, el impacto económico de una pandemia infligiría sufrimiento sustancial a todas las personas. Los recursos necesarios para prepararse en forma adecuada serán cuantiosos. Sin embargo, se les debe considerar a la luz del costo de dejar de invertir: una economía mundial que permanezca en ruinas durante varios años.

Estamos en un momento crítico de la historia. Se agota el tiempo para prepararnos ante la próxima pandemia. Debemos actuar ya, con decisión y propósito. Algún día, cuando la próxima pandemia haya llegado y se haya ido, se encargará a una comisión, muy parecida a la del 11 de septiembre de 2001, determinar con qué eficacia el gobierno, las empresas y los dirigentes de la salud pública prepararon al mundo para la catástrofe cuando habían recibido una advertencia clara. ¿Cuál será el veredicto? 